Research Journal of Dairy Sciences 4 (3): 18-22, 2010

ISSN: $1993-5277$

(C) Medwell Journals, 2010

\title{
Sensorial and Electrophoretic Analysis During the Ripening of Three Mono-Race Ewe Cheese
}

\author{
${ }^{1}$ Gianpiero Negrini, ${ }^{2}$ Anna Rita Lizzi, ${ }^{2}$ Arduino Oratore, ${ }^{2}$ Veronica Carnicelli and ${ }^{2}$ Antonio Di Giulio \\ ${ }^{1}$ Istituto Professionale di Stato per l'Agricoltura el'Ambiente, I-67100 L'AQuila (AQ), Italy \\ ${ }^{2}$ Dipartimento di Scienze e Tecnologie Biomediche, Universita Degli Studi L'Aquila \\ I-67010, Coppito-L'AQuila (AQ), Italy
}

\begin{abstract}
The flavour and final texture of cheese are the outcome of a series of chemical, biochemical and microbiological events that occur during ripening among them lipolysis, proteolysis as well as glycolytic events represent the more important. During the elaboration and ripening of the cheese, the casein are degraded several grades and their hydrolysis is one of the main determinants of the texture and flavor of the product. In this study, the cheese was obtained from milk of 3 different ewe races namely Comisana, Delle Langhe and Merinizzata Italiana. The cheese was sampled after 2, 30,60 or 90 days of ripening and evaluated for different sensory and structural characters (i.e., by visual, olfactory and gustative analysis) by a panel of expert assessors. The analysis of the panel was compared with electrophoretic pattern of cheese extract during the ripening. From the data, it appears that both the sensorial characters and the final texture of the 3 mono-race derived ewe cheese evolved in a sort of race-dependent way. These observations seems to indicate a fascinating scenario in which it is possible for the producers by an accurate blend of the starting mono-race milks and/or by modulate the ripening time of a mono-race derived cheese to better match the consumer preferences and requests.
\end{abstract}

Key words: Cheese extract electrophoresis, ewe cheese, proteolysis, sensory analysis, consumer, Italy

\section{INTRODUCTION}

The production of cheese from ovine milk represents one important sector in the agricultural economy for a number of countries, especially in the Mediterranean area (Cosentino and Palmas, 1997). In most regions of Italy, ewe milk is almost exclusively used for cheese manufacture and it is usually processed in small dairies which do not have sufficient technical and scientific knowledge for large-scale controlled production. As a consequence, a variety of traditionally made ewe cheese are in the market.

Now-a-days, the people is more exigent for the organoleptic properties of the dairy products and the flavour of a particular food product is one of the key attributes for the consumers (Smit et al., 2000). The final texture as well as the flavour of cheese are the effects of a complex series of events that take place during the ripening period (Irigoyen et al., 2001), among them lipolysis, proteolysis as well as glycolytic events represent the more important, an exhaustive review of the pathways involved has been recently published by Marilley and Casey (2004). Of the biochemical events, proteolysis is considered to be the most complex and important process for development of flavour and texture being known that the release of peptides and free amino acids are directly involved in bitterness and responsible for a contribute in the basic cheese flavour, respectively (Engels and Visser, 1994). One of the major contribute to the cheese evolution is the casein proteolysis exerted by the milk proteases, curd enzymes and starter micro organisms proteases. It is well known that ovine caseins show variants and genetic differences in the structure as well as minor components of ovine casein with a polypeptide chain similar to that of $\beta 1$ and 2 -caseins (Chianese et al., 1992).

Breakdown of the different caseins and changes occurring during ripening, i.e., formation of peptides have been studied in depth to detect between species variant and genetic differences (Chianese et al., 1992) as well as it is known that formation of macro and oligopeptides occurs during normal ripening (Izco et al., 1999). However, the final product (cheese) still remains the result of several events and conditions (i.e., milk, season, ewe race, manufacture, ripening, etc.), the majority of which are still unknown therefore, it is very difficult to address a specific characteristic of the cheese to one of them (Muir et al., 1995). The objective of this study is the evaluation of the ripening process of 3 cheese productions using milk of mono-race ewe and maintaining constant the other parameters. The sensory analysis was carried out by a trained panel of assessors of the Italian national cheese

Corresponding Auhtor: Gianpiero Negrini, Istituto Professionale di Stato per l'Agricoltura el' Ambiente, I-67100 L' AQuila (AQ), Italy 
tasting board and their responses were paralleled to the electophoretic analysis of the casein breakdown process.

\section{MATERIALS AND METHODS}

Cheese-making and samplings: The ewe's milk was obtained from the so called Comisana (CO), Delle Langhe $(\mathrm{DL})$ and Merinizzata Italiana $(\mathrm{ME})$ ewe race reported in the Asso.Na.Pa. (Associazione Nazionale della Pastorizia www.assonapa.it) public registry with the numbers 24,30 and 31 , respectively. Raw milk samples were collected from the three flocks on the morning of cheese-making and transported to the pilot plan. After filtration of the milk and separation of the samples for the physicochemical analyses, the cheese was manufactured at the pilot plant according to the traditional protocol of the Abruzzi ewe cheese production as follows. The crude milk whose fat and proteins contents are shown in Table 1 was heated at $22^{\circ} \mathrm{C}$ and milk containing starter constituted by thermopile micro organisms and allowed to researchers for $30 \mathrm{~min}$. Then, the milk was heated up to $37^{\circ} \mathrm{C}$ and the curdle $(50 \mathrm{~mL} / 100 \mathrm{~L}$ of milk) added after $20 \mathrm{~min}$ of coagulation, the resulting curd was sliced and stirred for $30 \mathrm{~min}$ and re-heated up to $44^{\circ} \mathrm{C}$ to facilitate the whey drainage.

The curd was packed in cylindrical moulds pressed and weighted at room temperature. For each milk type, 6 cheese samples of about $250 \mathrm{~g}$ were prepared. The cheese was placed at $28^{\circ} \mathrm{C}$ in an airing, temperature and humidity controlled chamber for $6 \mathrm{~h}$ and successively, treated with $\mathrm{NaCl}$, this last procedure was repeated after further $24 \mathrm{~h}$.

The ripening of the cheeses was done in an airing chamber for 7 days at $14^{\circ} \mathrm{C}$ and successively, at $10^{\circ} \mathrm{C}$ with a relative controlled humidity of $75 \%$. The weighting procedure was repeated after $1,2,3,7,14$ and 30 days from the manufacture to verify the weight loss during the ripening process. During the ripening period, the cheese crust was treated with olive oil. After $2,30,60$ or 90 days one sample of each cheese was withdrawn divided in slices and used for the sensory and electrophoretic tests.

Sensory analysis: Cheese samples after 2, 30,60 or 90 days of ripening were analysed by a panel of expert

\begin{tabular}{lccc}
\multicolumn{4}{l}{ Table 1: Ewe milk characteristics } \\
\hline Ewe race & Delle Langhe (DL) & Merinizzata (ME) & Comisana(CO) \\
\hline Fat & 6.70 & 9.34 & 7.21 \\
Proteins & 5.99 & 6.70 & 5.66 \\
Caseins & 5.07 & 5.71 & 4.72 \\
Casein index & 0.85 & 0.85 & 0.83 \\
Lactose & 4.39 & 4.37 & 4.25 \\
Dry matter & 17.22 & 18.54 & 18.79 \\
\hline
\end{tabular}

aThe casein index is obtained by dividing the casein content for the total protein content assessors all members of the Italian national cheese tasting board, ONAF. Each sample was evaluated by at least five trained assessors according to the ONAF rules.

The attribute were evaluated by visual, olfactory and gustative analysis. The cheese external appearance, odour and aroma intensities as well as the texture components such as elasticity, rigidity, deformability, friability, adherence, solubility and humidity were considered together with the sweetness, saltiness, acidity, bitterness, pungency and aftertaste persistence of the samples. Intensity of each attribute was reported in a scale from 0 (absent) to 5 (elevated).

\section{Electrophoresis of cheese extract}

Extraction of casein: An amount of $10 \mathrm{~g}$ of (comminuted) different types of ewe's cheese was weighed out and $1 \mathrm{M}$ sodium acetate buffer, $\mathrm{pH} 4.6$ was added. The misture was homogenized using a teflon pestle, left a $4^{\circ} \mathrm{C}$ for $30 \mathrm{~min}$ and centrifuged at $4500 \mathrm{~g}$. The lipid fraction remaining in the casein precipitate was removed by washing with dichloremethane-acetate buffer $(1: 1, \mathrm{v} / \mathrm{v})$. The precipitate was washed with acetone and left to dry in a speedvac at $30^{\circ} \mathrm{C}$. Finally, the casein was comminuted to the smallest possible grain size. The dried powdered casein was stored at $-20^{\circ} \mathrm{C}$ until analysis (Izco et al., 1999).

Sample preparation and electrophoretic analysis: Casein solution was prepared by dissolving $1 \mathrm{~g}$ casein of $100 \mathrm{mM}$ Tris- $\mathrm{HCl}$ buffer ( $\mathrm{pH} \mathrm{8.0)}$ and heating in a boiling bath for $20 \mathrm{~min}$. The solution was filtrated without cooling and stored until to be used. Casein solution were diluted by sample buffer and heated at $100^{\circ} \mathrm{C}$ for $5 \mathrm{~min}$ (Pardo and Natalucci, 2002).

Solutions for the gels were prepared according to Shagger and von Jagow (1987) without modifications. The electrophoresis was performed in a mini-protean III dual slab cell (Bio-Rad Laboratories, Watford, UK). Immediately after ending electrophoresis, gels were placed in a fixative solution containing 50\% methanol and 10\% acetic acid for $1 \mathrm{~h}$ and then stained with a solution containing $10 \%$ acetic acid and $0.1 \%$ Coomassie Brillant Blue $(\mathrm{CBB})$ in which the gels were left for $1 \mathrm{~h}$ at room temperature. The gels were then destained with several changes of distillated water.

\section{RESULTS AND DISCUSSION}

The complex biochemical events which take place during cheese ripening, such as proteolysis, glycolysis and lipolysis, caused mainly by activity of enzymes and microrganisms, transform the taste-poor curd into the mature product with peculiar characters. Among them as reported by several researchers (Law et al., 1993; 
Engels and Visser, 1994), the proteolysis has been considered the most complex and important process for development af final product flavour and texture. In this scenario, we followed the evolution of the sensorial characters of 3 mono-race ewe cheese paralleling the evaluation of the sensory panel with the electrophoretic profile of the cheese extract.

The macronutrients content patterns of the starting ewe milk (Table 1) showed a similar casein index (ratio between casein and total protein content) even if the milks differ in their total dry matter content in particular fat and total proteins both higher in the ME race. We transformed the 3 milk samples in curd using in the same way (i.e., plant, rennet and starters) and successively we treated the derived curds in identical conditions as reported in this study to reduce the influence of external variable in the cheese ripening and correlate sensorial evolution processes. After only 2 days of ripening, the first sample of each cheese was withdrawn and evaluated by the sensory panel. The differences in sensorial attributes as presumable were few or absent except for the saltiness and adherence less pronuonced in the ME sample with respect to the other two. Also, the electrophoresis pattern of the cheese extract at this stage of ripening do not differ significantly. When the cheese evolution proceed the 3 cheese samples developped peculiar characteristics more pronounced after 90 days of ripening as evidenced in the radar plots (Fig. 1a, b). It is clear that the main changes in sensory character associated with ripening of the samples are increases in their aroma and odour together with the devolopment of their characteristic taste and structural characters (Table 2). All these parameters are undoubtedly influenced by several factors: milk quality, coagulant, starter and adventitious growth in cheese of non-starter lactic acid bacteria. So that in

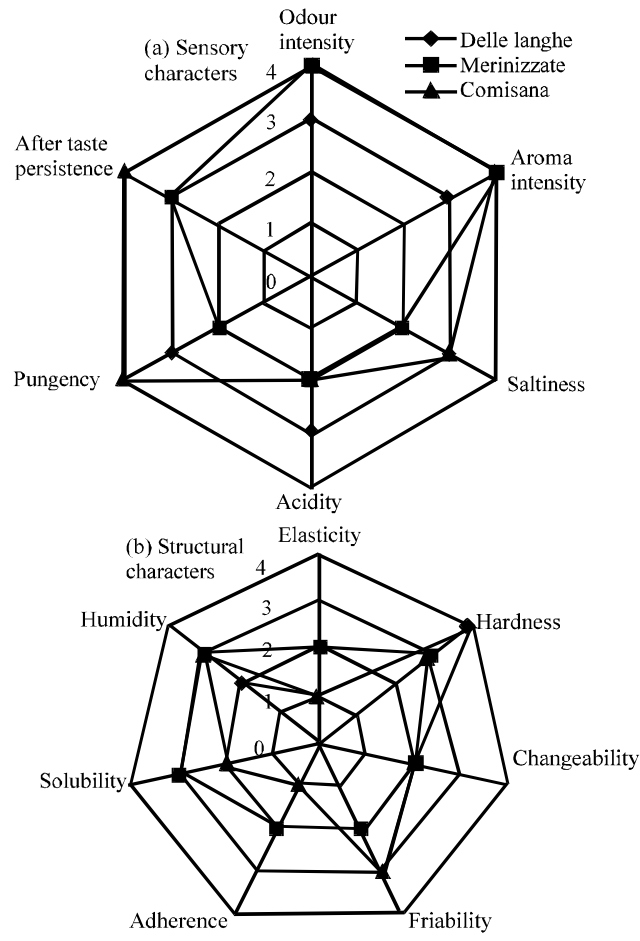

Fig. 1: Ewe cheese sensory and structural characters after 90 days of ripening

\begin{tabular}{|c|c|c|c|c|c|c|c|c|c|c|c|c|}
\hline \multirow[b]{2}{*}{ Ripening time (days) } & \multicolumn{4}{|c|}{ Delle Langhe (DL) } & \multicolumn{4}{|c|}{ Merinizzata (ME) } & \multicolumn{4}{|c|}{ Comisana (CO) } \\
\hline & 2 & 30 & 60 & 90 & 2 & 30 & 60 & 90 & 2 & 30 & 60 & 90 \\
\hline \multicolumn{13}{|l|}{ External appearance } \\
\hline Shape ${ }^{\mathrm{a}}$ & $\mathrm{R}$ & $\mathrm{R}$ & $\mathrm{R}$ & $\mathrm{R}$ & $\mathrm{R}$ & $\mathrm{R}$ & $\mathrm{R}$ & $\mathrm{R}$ & $\mathrm{R}$ & $\mathrm{R}$ & $\mathrm{R}$ & $\mathrm{R}$ \\
\hline Surface $^{a}$ & $\mathrm{R}$ & $\mathrm{R}$ & $\mathrm{R}$ & $\mathrm{R}$ & $\mathrm{R}$ & $\mathrm{R}$ & $\mathrm{R}$ & $\mathrm{R}$ & $\mathrm{R}$ & $\mathrm{R}$ & $\mathrm{R}$ & $\mathrm{R}$ \\
\hline \multicolumn{13}{|l|}{ Internal appearance } \\
\hline Rind $(\mathrm{mm})$ & 0.5 & 3.0 & 3.5 & 4.0 & 0.5 & 3.0 & 4.0 & 5.0 & 0.5 & 2.0 & 3.0 & 4.0 \\
\hline Colourb & W & SY & SY & SY & $\mathrm{CY}$ & OY & OY & OY & W & $\mathrm{CY}$ & $\mathrm{CY}$ & $\mathrm{CY}$ \\
\hline \multirow{2}{*}{\multicolumn{13}{|c|}{ Olfactory characters }} \\
\hline & & & & & & & & & & & & \\
\hline Odour intensity & 1 & 2 & 2 & 3 & 1 & 2 & 3 & 4 & 1 & 2 & 3 & 4 \\
\hline Aroma intensity & 1 & 2 & 2 & 3 & 1 & 2 & 3 & 4 & 1 & 2 & 3 & 4 \\
\hline \multicolumn{13}{|l|}{ Taste characters ${ }^{\mathrm{d}}$} \\
\hline Sweetness & 2 & 2 & 2 & 2 & 1 & 2 & 2 & 2 & 2 & 2 & 2 & 2 \\
\hline Saltiness & 4 & 3 & 3 & 3 & 2 & 2 & 2 & 2 & 4 & 3 & 3 & 3 \\
\hline Acidity & 1 & 1 & 1 & 1 & 1 & 1 & 1 & 1 & 1 & 1 & 1 & 1 \\
\hline Bitterness & 1 & 1 & 1 & 1 & 1 & 1 & 1 & 1 & 1 & 1 & 1 & 1 \\
\hline Pungency & 0 & 1 & 2 & 3 & 0 & 1 & 1 & 2 & 0 & 1 & 2 & 3 \\
\hline Aftertaste persistance & 2 & 2 & 3 & 4 & 2 & 3 & 3 & 3 & 2 & 3 & 4 & 4 \\
\hline \multicolumn{13}{|l|}{ Structural characters ${ }^{\mathrm{d}}$} \\
\hline Elasticity & 3 & 1 & 1 & 1 & 3 & 1 & 1 & 1 & 2 & 1 & 1 & 1 \\
\hline Hardness & 2 & 3 & 3 & 4 & 2 & 3 & 3 & 3 & 2 & 3 & 3 & 3 \\
\hline Changeability & 3 & 1 & 1 & 1 & 3 & 1 & 1 & 1 & 2 & 1 & 1 & 1 \\
\hline Friability & 1 & 2 & 2 & 3 & 1 & 2 & 2 & 2 & 1 & 3 & 3 & 3 \\
\hline Adherence & 3 & 1 & 1 & 1 & 1 & 1 & 2 & 2 & 3 & 1 & 1 & 1 \\
\hline Solubility & 1 & 1 & 1 & 1 & 1 & 1 & 2 & 3 & 1 & 1 & 1 & 1 \\
\hline Humidity & 3 & 1 & 1 & 1 & 3 & 1 & 1 & 1 & 3 & 1 & 1 & 1 \\
\hline
\end{tabular}

${ }^{a} \mathrm{R}=$ Regular $; \mathrm{NR}=$ Not Regular, $\mathrm{A}=$ Absent; ${ }^{\mathrm{b}}$ Colours: $\mathrm{W}=$ White; $\mathrm{SY}=$ Straw Yellow; $\mathrm{CY}=$ Cream Yellow; OY = Ochre Yellow. ${ }^{\mathrm{c}}$ Holes; $\mathrm{F}=$ Fine, $\mathrm{M}=$ Medium $^{\mathrm{d}} 0=$ Not perceivable; $1=$ Very low; $2=$ Low, $3=$ Medium; $4=$ High; $5=$ Elevated 
Res. J. Dairy Sci., 4 (3): 18-22, 2010

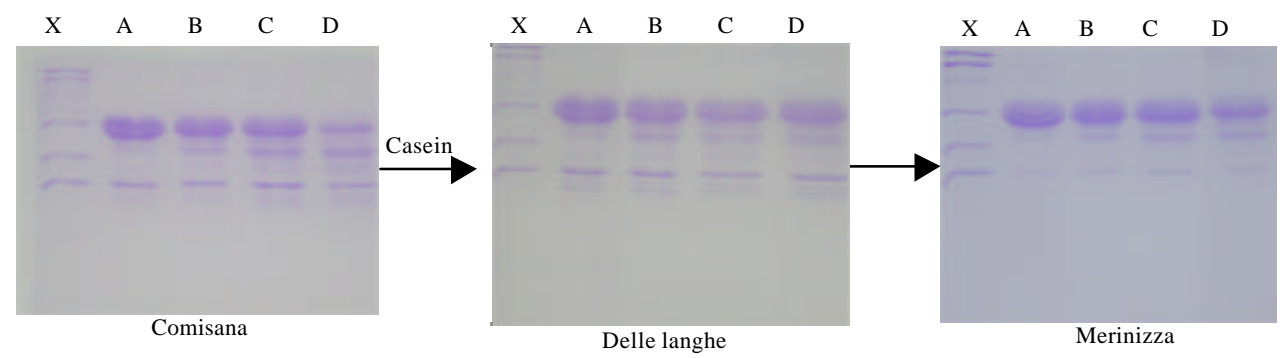

Fig. 2: Electrophoretic pattern of cheese extracts. ${ }^{a}$ Sample after 2 days (A), 30 days (B), 60 days (C) and 90 days (D) of ripening. $\mathrm{X}=$ Molecular weight

the same condition of cheese making procedures and ripening, these changes can be ascribed mainly to the composition of starting (race) milk. In particular, we found that the samples from $\mathrm{ME}$ and $\mathrm{CO}$ races showed earliest the characteristic ewe cheese flavour and aroma whereas the spicy character appeared in $\mathrm{CO}$ e DL samples more intense that in the ME.

It is well known that several organoleptic properties of cheese might be attributed to the release of peptides and amino acids and their successive transformations which occur during the ripening (Marilley and Casey, 2004).

In particular, the solphur notes of the well-ripened ewe cheese, defined by the panelists as garlic or boiled potato or cooked gabbage flavours, depend directly from the methionine catabolism (Yvon and Rijnen, 2001) as well as the malty flavour might be attributed to the derivative of the branched chain ammino acids and the honey-like and floral flavours when present, to the catabolism of aromatic amminoacids (Thierry and Maillard, 2002). In the tests as in other sensory analysis, the panel should be seen as an instrument and for this reason as suggested by Mcewan et al. (2002), we paralleled to the assessors evaluations a more objective analysis in this case the electrophoresis of the cheese extract of the same samples. From this analysis, it appears that in the $\mathrm{CO}$ samples the protein degradation occurs faster than in the other two cheese extracts.

In fact, the bands at higher molecular weight diminished in intensities with a concomitant appearance of casein degradation products, evident as protein bands with high electrophoretic mobility, faster than in the other 2 cases. In fact, the band at $45 \mathrm{kDa}$ after 90 days of ripening diminished of about $50 \%$ and the band at $35 \mathrm{kDa}$ and low molecular weight progressively increased being well defined after 30 days of ripening as a sign of a faster cheese maturation.

Whereas in the case of ME samples, the bands at low molecular weight are well defined only at the end of the observation period (Fig. 2). The evolution of the 3 extracts electoporetic patterns although, not quantitative, seems to confirm a different cheese maturation during the ripening as indicated by the panel.

\section{CONCULUSION}

From the data, it appears that both the sensorial characters and the final texture of the 3 mono-race derived ewe cheese evolved in a sort of race-dependent way. These observations seems to indicate a fascinating scenario in which it is possible for the producers by an accurate blend of the starting mono-race milks and/or by modulate the ripening time of a mono-race derived cheese to better match the consumer preferences and requests.

\section{REFERENCES}

Chianese, L., R. Mauriello, L. Moio, N. Intorcia and F. Addeo, 1992. Determination of ovine casein heterogeneity using gel electrophoresis and immunochemical techniques. J. Diary Sci., 59: 39-47.

Cosentino, S. and F. Palmas, 1997. Hygienic conditions and microbial contamination in six ewe's-milkprocessing plants in Sardinia, Italy. J. Food Protect., 60: 283-287.

Engels, W.J.M. and S. Visser, 1994. Isolation and comparative characterization of components that contribute to the flavor of different types of cheese. Netherland Milk Dairy J., 48: 127-140.

Irigoyen, A., J.M. Izco, F.C. Ibanez and P. Torre, 2001. Influence of rennet milk-clotting activity on the proteolytic and sensory characteristics of an ovine cheese. Food Chem., 72: 137-144.

Izco, J.M., A.I. Ordonez, P. Torre and Y. Barcina, 1999. Validation of capillary electophoresis in the analysis of ewe's milk casein. J. Chromatogr. A, 832: 239-246.

Law, J., G.F. Fitzgerald, T. Uniacke-Lowe, C. Daly and P.F. Fox, 1993. The contribution of lactococcal starter proteinases to proteolysis in cheddar cheese. J. Dairy Sci., 76: 2455-2467. 
Marilley, L. and M.G. Casey, 2004. Flavours of chesse products: Metabolic pathways, analytical tools and identification of producing strains. Int. J. Food Microbiol., 90: 139-159.

Mcewan, J.A., E.A. Hunter, L.J. van Gemert and P. Lea, 2002. Profiency testing for sensory profile panels: Measuring panel performance. Food Quality Preference, 13: 181-190.

Muir, D.D., E.A. Hunter, J.M. Banks and D.S. Horne, 1995. Sensory properties of cheddar cheese: Changes during maturation. Food Res. Int., 28: 561-568.

Pardo, M.F. and C.L. Natalucci, 2002. Electrophoresis analysis (Tricine-SDS-PAGE) of bovine caseins. Acta Farmacol. Bonaerens, 21: 57-60.
Shagger, H. and G. von Jagow, 1987. Tricine-sodium dodecyl sulfate-polyacrylamide gel electrophoresis for the separation of proteins in the range from 1 to $100 \mathrm{kDa}$. Anal. Biochem., 166: 368-379.

Smit, G., A. Verheul, R. van Kranenburg, E. Ayad, R. Siezen and W. Engels, 2000. Cheese flavour development by enzymatic conversions of peptides and amino acids. Food Res. Int., 33: 153-160.

Thierry, A. and M.B. Maillard, 2002. Production of cheese flavour compounds derived from amino acid catabolism by Propionobacterium freudenreichii. Lait, 82: 17-32.

Yvon, M. and L. Rijnen, 2001. Cheese flavour formation by amino acids catabolism. Int. Dairy J., 11: 185-201. 